\title{
The Influnces of Telecommuting on Teleworkers Skills
}

\author{
Dr. Ahmed Yass Algrari \\ Cihan University/sulymainya /Kurdistan region/Iraq
}

\begin{abstract}
Abstruct: This paper identifies the positive and negative influences of telecommuting on the teleworkers. Some recommendations concerning the atributes of telecommuting to make the teleworkers more independent . In addition, the paper reviews the existing literature to identify factors leading to successful telecommuting programs, especially with regards to choosing the appropriate jobs and the sutable technologies to make the telecommuting a success job. Furthermore, this paper lists several telecommuting rules and policy.
\end{abstract}

Keywords: information technology, telecommting,teleworking, telecommuter,teleworker.

\section{Introduction}

Information Technology (IT) has grown and evolved over the last 50 years; you cannot think and plan a project, business or other initiative without the usage of this technology. When we sayInformation Technology that means not only personal computers or smart phones, but also modern machinery in factories, automotive industry, aviation industry, various household appliances etc., In one way or another this has not only facilitated our daily lives but it has also reduced cost and time in general. the great opportunities that Information Technology and the Internet provide as an important tool for implementation in organizations and public institutionsTelecommuting or Teleworking has been the subject of numerous debates, articles, and academic papers - and in my opinion, the difference is minimal. The term "telework" tends to be used more in Europe and some other countries, while "telecommuting" is used more in the U.S. Some people prefer the word "telework" because it's a more accurate description of the concept - the "tele" prefix means "distance", so "telework" means "work at a distance." The telework advocates also believe that "telecommuting" has too strong a connotation about the commuting aspect, and that "telework" is a broader and more inclusive terms. Whatever you choose to call it, the underlying concept is the same: decentralizing the office, and using different ways of bringing the work to the workers. It doesn't make much difference what you call it[1].

\section{Definition And Components Of Telecommuting (Teleworking)}

Telecommuting (teleworking) can be defined as a "work arrangement in which employees perform their regular work at a site other than the ordinary workplace, supported by technological connections" ([2]. Telecommuting represents an expansion of the places and times considered auspicious for work. Three principal components of telecommuting can be identified [3] utilization of information technology (IT), link with an organization, and de-localization of work. First, telecommuting depends on the processing, manipulation, and transformation of information. Thus, IT represents one of the major components of telecommuting because it enables workers to be in constant communications with their organization and their colleagues. Second, contrary to independent workers, telecommuters have ties with an organization [4]. Telecommuting is not limited to permanent workers, as employees working on a contractual basis may also telecommute. However, distinctions exist between the type of telecommuting that is prevalent in each group. Authors generally recognize that telecommuting by contractual employees engenders a greater number of difficulties[5]. This type of telecommuting usually includes clerical work where employees are remunerated on a piecemeal basis, or more infrequently, on an hourly basis. Moreover, [2] has suggested that the negative impacts generally attributed to home-based telecommuting do not stem from the location itself, but rather, from the contractual nature of the arrangement. Third, telecommuting is not constrained by time and space [3]. The de-localization of work takes four main forms: telecommuting from home (home-based), satellite offices, neighborhood work centers, and mobile work. Home-based telecommuting is usually performed in a dedicated area of the worker's place of residence. For this type of telecommuting, equipment installation fees are usually subsidized, entirely or in part, by the organization[4]. Satellite offices takes the form of a small organizational affiliates generally located in proximity to residential areas where a telecommunications link with headquarters is permanently maintained [5]. This type of telecommuting represents an interesting compromise for organizations that desire to keep their employees in more traditional surroundings but closer to their homes. A distinction can be made between satellite offices and neighborhood work centers. The later are not organizational units, but instead, are private information centers that possess telecommunication tools that are generally shared by employees from various enterprises . Mobile work, on the other hand, is a form of telecommuting that is not limited to any specific "brick and mortar" location. Mobile work empowers employees with the capacity to perform activities in 
different places and in an ad-hoc fashion, such as, in a car, in a plane or in a hotel room. It includes such advantages as enabling better and more personalized customer service by allowing organizations to dispatch sales representatives directly to customer locations. Therefore, telecommuting is not restricted to any one particular form and is not limited to working from home on a full time basis.

\section{Technologies to Make Telecommuting A success}

3.1.Thin Client enables employees to remotely access a variety of common Windows applications through a Web browser from any location with an Internet connection. The system works on both Windows and Mac computers.[6]

3.2. Virtual Private Network creates an encrypted Internet "tunnel" between your computer and the agency network. This ensures that documents, files, and data that you access can only be seen by you and not someone else.[7]

3.3. Online Meeting is a collaborative conference tool that enables online meeting participants to share information virtually. Participants from varying locations can all view the same presentation on their computer screen, while editing and revising documents (Word, Excel, and PowerPoint).[8]

3.4. Instant Messaging is a feature that makes real time communication quick and easy.

3.5. Tetheringenables users to connect their computer to the Internet by using a mobile device for an internet connection. [9]

3.6 .Voice over IP (VoIP) is a telephone system that simplifies communication, encourages telework, and saves money by using the Internet rather than traditional telephone lines to make phone calls.[10]

\section{Telecommuting Rules And Policy}

Telecommuting is a method of reducing air pollution, reducing congestion, conserving energy, increasing employee productivity and efficiency, and retaining a creative, experienced, and diverse work force. This policy is intended to apply to formalized, contractually-agreed upon telecommuting projects where working at an alternate location is a routinely scheduled occurrence. It is not intended for ad hoc, short-term situations where employees work at home on special occasions to complete specific projects. [11]

\section{Recommended Policy}

4.1. Telecommuting is neither a universal employee right nor a universal employee benefit; telecommuting is a management option which may be made available to some employees when a mutually beneficial situation exists, the agency, and the employee. Telecommuting contracts may be terminated at any time the beneficial situation ceases to exist for USDA, Departmental Administration or the staff office.

4.2. Employees do not have an obligation to telecommute nor can they be compelled to telecommute. An employee may return to the conventional office arrangement at any time if they wish to withdraw from telecommuting.

4.3. Each agency must establish a telecommuting policy within the framework of the Departmental Administration policy.

4.4. Every employee involved in a formal telecommuting project must complete and agree to a telecommuting agreement.

4.5. Telecommuting employees should be encouraged to use supplied computers for telecommuting, if feasible. No DA employee should be compelled to use privately-owned computer equipment. If DA equipment is used, the employee must exercise reasonable care for the equipment. The employee may be held liable for damage caused by negligence. If employee-supplied computers are used, the employee must release USDA and DA from any and all liability.

4.6. Telecommuting employees must comply with all applicable laws, state administrative rules, USDA, and agency rules. The employee may not copy or distribute provided software. The employee may not install unauthorized hardware or software on Departmental Administration owned equipment. [12].

\section{The Attributes of Telecommuting}

5.1. Ability to work independently andwith minimal supervision, self-motivated, with a good solid historyof job performance appraisals.

5.2. They are flexible, goal-oriented,with good organizational, planningand time management skills.

5.3. Ability to separate job demandsfrom home and family needs [13]. 


\subsection{Positive influences}

\section{The Influnce of Telecommuting on Tele workers}

\subsubsection{Reduction/ elimination of transport time [14]}

6.1.2 Cost savings related to work habits (e.g., travel, clothing and food)[14].

6.1.3. Flexibility in the organization of work hours and leisure activities ([14]

6.1.4. Increase in Productivity [14].

As indicated above, telecommuting can have influences on teleworkers. One of the major benefits of telecommuting stems from the elimination or reduction of the time needed to physically commute to work. [15]note that $75.5 \%$ of the 62 part-time telecommuters (i.e. managers and professionals) they interviewed reported that telecommuting allowed them to save over one hour a day in commuting. By reducing the time and distance that must be traveled to work or by completely avoiding traditional forms of commuting, telecommuting can help alleviate high levels of stress. Moreover, telecommuting provides individuals with the potential to reconcile their personal lives with their work-related obligations. It provides individuals with more freedom in managing their time between work, leisure activities, and family responsibilities [16]. In a survey of 20 part-time telecommuters, increased flexibility and personal control over work and life were judged as being the most important motivators for telecommuting [17]. In fact, this increased flexibility seems to be the cause of higher levels of employee satisfaction and productivity. Ninety percent of Northern Telecom's (Nortel) telecommuters reported greater job satisfaction and $73 \%$ of them reported experiencing a decrease in stress level ([18]. [19]note that telecommuting allows individuals to be more productive because it enables them to work when their creativity is high (which for some employees may not correspond with regular office hours). Also, telecommuting lowers the number of distractions in the traditional office environment, thus allowing greater concentration and focus on important tasks [20]. The results of a survey of 20 telecommuters indicate that $58 \%$ of them believed that greater tranquility allowed them to be more productive [20]. Similarly, [21] suggest that it is the lower number of interruptions and the increase in attention and motivation due to the elimination of the stress caused by daily commuting that lead to productivity gains. Telecommuting can also lower the costs associated with work, such as travel, clothing and restaurants [22].

\subsection{Negative influences}

6.2.1.Feeling of isolation [19].

6.2.2. Reduction in chances of promotion [19].

6.2.3. Tendencies to overwork [20].

6.2.4. Potential decrease in frequency of intra-organizational communication for full-time telecommuters (teleworkers)[21].

Telecommuting may also produce some undesirable effects on individuals. For example, recently, the German Union of Bank Employees has raised several concerns related to telecommuting such as: increased levels of overwork, the invasion of personal life, a loss of confidentiality, the lack of adequate feedback related to work performance, and with the social isolation of telecommuters. In fact, feelings of isolation and the loss of morale are the most commonly cited drawbacks of telecommuting [17]. In a study conducted with 103 telecommuters, $29 \%$ of respondents identified being left out of office communications and the feeling of isolation as important disadvantages of telecommuting [16]. Also, [21] reported that 23\% of supervisors $(n=17)$ believed that communication problems had arisen during a pilot project conducted at Statistics Canada. However, very little empirical evidence exists to substantiate these claims. In factargues that the loss of morale does not depend on the particular work environment in which the telecommuter works, but rather, to events concerning the type of work itself. Also, lower morale might happen during the first weeks of telecommuting because individuals can feel isolated at first. [21]Describes one unit using a 'buddy system' where remote workers contact on-site colleagues each morning. Their topics of conversation are not restricted; instead, the company wishes to promote informal chats about a variety of topics that employees used to engage in "around the water cooler in a commercial office". Companies can stimulate social interactions between co-workers and telecommuters and reduce feelings of isolation by limiting the number of days employees telecommute to less than five and making sure that telecommuters attend company meetings and social events [22]. Another potential negative impact related to telecommuting is the emergence of conflicts between family and work related roles [19]. Such situations usually arise when telecommuters, working from their homes, become less productive because distractions and interruptions abound [22]. Not surprisingly, results from a survey conducted with 97 telecommuters showed that family disruptions were significantly negatively correlated with telecommuting satisfaction $(\mathrm{p}=0.004)$ [22]. However, such problems can generally be avoided by ensuring that one room in the home is reserved specifically for telecommuting purposes and that family member's support the initiative [14]. 


\section{Conclusion}

This paper highlighted several important influences of telecommuting on the employees. Advantages for telecommuter include lower levels of absenteeism, increased levels of employee loyalty, a better retention of skilled employees, increased productivity, cost savings, increased flexibility, and the potential to quickly recover from interruptions due to unexpected events such as natural disasters. However, telecommuting is also associated with some undesirable effects such as the absence of employees from the office, a loss of synergy within the organization, and a lower security and control of organizational data. Moreover, several authors have noted that managers often experience difficulty in supervising and objectively evaluating the performance of telecommuters. Furthermore theinfluences include time and cost savings, reductions in stress levels, more flexible working hours, and fewer interruptions, which are likely to lead to greater job satisfaction and increased productivity. However, telecommuting can also lead to feelings of isolation and a loss of morale.

\section{References}

[1]. Douglas, K. (2002). Sociological Theory. Vol. 20, No. 3, 285-305.

[2]. Fitzer, M. M. (1997). Managing from Afar: Performance and Rewards in a Telecommuting Environment, Compensation and Benefits Review, 29 (1), January-February, 65-73.

[3]. Pinsonneault, A., and Boisvert, M. (1996). Le Teletravail: L'organisation de Demain?,Gestion, 21 (2), 76-82.

[4]. Bailyn, L. (1994). Toward the Perfect Workplace?The Experience of Home-Based SystemsDevelopers. In Allen, T. J. and Scott Morton, M. S. (Eds.) Information Technology and the Corporation of the 1990s : Research Studies New York: NY, Oxford University Press, 410-429.

[5]. Huws, U. (1984). The New Homeworkers : New Technology and the Changing Location of White Collar Work, Low Pay Unit, London:UK

[6]. Nilles, J. M. (1994). Making Telecommuting Happen, Van Nostrand Reinhold, New York: NY.

[7]. Gordon, G. E. and Kelly, M. M. (1986). Telecommuting: How to Make it Work for You and Your Company, Prentice Hall, Englewood Cliffs: N.J.,

[8]. Doswell, A. (1992). Home alone? - Teleworking. Management Services, October, 18-21

[9]. Olson, M. H. (1987a). Telework: Practical Experience and Future Prospects, in R.E. Kraut (ed.), Technology and the Transformation of White Collar Work, Lawrence Erlbaum Associates, Hillsdale: NJ, 135-152

[10]. Davenport, T. H. and Pearlson. K. (1998). Two Cheers for the Virtual Office, Sloan Management Review, 39(4), 51-65.

[11]. Gordon, Gil, 1999. "What Will Telework Change and What Kind of Future Will it Bring?Today and Tomorrow in the Leading Telework Country," Presented at FourthInternational Telework Workshop, Tokyo, Japan, September 3, 1999.

[12]. APGAR, M. (1998). The alterantive workplace: changing where and how people work. Harvard Business Review, 76, 121$\} 135$.

[13]. Shaw, Lisa. Telecommute! Go to Work Without Leaving Home.John Wiley \&Sons, Inc. New York. 1996.

[14]. Baruch, Y., and Nicholson, N. (1997). Home, Sweet Work: Requirements for Effective Home Working, Journal of General Management, 23 (2), 15-30.

[15]. DeSanctis, G. (1983). A Telecommuting Primer, Datamation, 29, 214-220.

[16]. Chapman, A. J., Sheehy, N. P., Heywood, S., Dooley, B., and Collins, S. C. (1995). The Organizational Implications of Teleworking. In Cooper, C. L. and Robertson, I. T. (Eds), International Review of Industrial and Organizational Psychology. John Wiley and Sons, New York: NY, 229-248.

[17]. Fitzer, M. M. (1997). Managing from Afar: Performance and Rewards in a Telecommuting Environment, Compensation and Benefits Review, 29 (1), January-February, 65-73.

[18]. Ramsower, R.M. (1985). Telecommuting : The Organizational and Behavioral Effects of Working at Home, Ann Arbor, MI: UMI Research Press.

[19]. Reinsch, N. L., Jr. (1997). Relationship Between Telecommuting Workers and their Managers: An Exploratory Study, The Journal of Business Communications, 34 (4), 343-369.

[20]. Knight, P. J., and Westbrook, J. (1999). Comparing Employees in Traditional Job Structures vs. Telecommuting Jobs Using Herzberg's Hygienes and Motivators, Engineering Management Journal, 11 (1), March, 15-20.

[21]. McCune, J. C. (1998). Telecommuting Revisited, Management Review, February, 1998, 10-16.

[22]. Richter, J. and Meshulam I. (1993). Telework at Home: The Home and the Organization Perspective, Human Systems Management, $12,193-203$ 